\title{
Policy reforms in agriculture and farmer's income diversification decision: The case of eggs farms
}

\author{
Rachel Lipshits*, Sagit Barel-Shaked **
}

DOI: $10.30682 / \mathrm{nm} 2102 \mathrm{e}$

JEL codes: A12, C13, C35, C38, Q18, R25

\begin{abstract}
Reforms in agriculture have become an integral part in policymaker's agenda. Research on past reforms in various sectors showed their effect on farmer's decision making regarding the continuum of farm work. This research objective is to expand and predict implications of emerging policy reforms on eggs branch farmers economics' viability. The theory presented here aims to analyze the farmer's decision making on income diversification by accounting for socio-demographics, wealth, and peripherality. The study of income diversification that is presented here can throw light on how risky the reforms are for farmers that their income is exclusively based on agriculture. Logistic regression and classification tree were employed in analyzing a sample of eggs producers in Israeli's periphery. The main findings signify that the younger, educated, and wealthier farmers who are more peripheral, prone towards diversifying income. Policymakers should acknowledge this variability in potential risks while designing agricultural reforms.
\end{abstract}

Keywords: Reforms in agriculture, Eggs branch, Income diversification, Logistic regression, Classification tree

\section{Introduction}

The rise of issues concerning environmental standards, animals' welfare restrictions, cost of living and free markets have led to major structural reforms in Israeli agriculture sector, initiating in the 90's. Structural changes in agriculture, in some countries, have been found risky for farmers that their income is exclusively based on agriculture (Hill, 1993; Kimhi and Reznik, 2018; Præstholm and Kristensen, 2007).

One strategy to reduce economic risk is by diversifying farm households' income resources (Weltin et al., 2017). Engaging in rural enterprises such as farm tourism activities is an ex- ample for diversification (Fleischer et al., 2018). Laven et al. (2019, p. 87) argues that "Tourism has become a go-to strategy for economic development in the peripheries, since it holds promise for generating income under conditions when other sectors fail, while also being characterized by low skill requirements and low barrier to entry (Brouder, 2013; Müller and Jansson, 2006)".

Other common strategy is off-farm work (Mishra and Goodwin, 1997; Serra et al., 2005; Weltin et al., 2017).

The purpose of this study is to assess economic implications of the emerging eggs farm policy reform in Israel. Specifically, the study aims to

\footnotetext{
* ORT Braude College, Karmiel, Israel.

** Western Galilee College, Akko, Israel.

Corresponding author: 1rachel.ym@gmail.com
} 
assess the ability of farmers to remain economically viable, by analyzing farmers income diversification strategies. A good understanding of the impacts of past agricultural reforms on farmers economic viability is twofold. It is essential for designing an effective eggs farm policy reforms and for gaining better understanding on farmers' income diversification strategy.

The Israeli poultry sector i.e., broiler, turkey and egg branches, was operated under heavy regulation indicated by allocation of production quotas. These quotas were banned for trading. At the beginning of the 90's a farm policy reform terminated the regulation in the broiler and turkey branches. Thus, Israeli poultry farmers excluding the egg branch, for the first time, could trade production quotas. Consequently, part of the farmers benefited from this opportunity and extended their production; businessmen were attracted to invest in this sector. The reform included requirements that meet animal health and welfare, food safety and quality standards. The only branch that remained under regulation is the egg branch.

These changing conditions have raised barriers for smallholder farmers. The result was a rapid exit of producers, an increase in the size of existing producers either through purchasing quotas or through mergers. For example, pre-reform, there were 3000 smallholder farmers in the broiler branch, post-reform in 1997, remained 1300 and since then its number declined considerably.

Analyzing the farmers adopting or nonadopting to past reforms can be used to predict the eggs branch households' farms economic sustainability and viability, as cited by Pannell and Zilberman (2020, p. 5) "Predicting adoption, not just explaining past adoption".

A better design of the reforms, ensuring farmers income stability, might led to different results with respect to the abandonment of smallholder farmers. Addressing income stabilization goal, Israelis' government support is required to assist farmers to cope with the changing conditions. A support that is missing in the 90'' reform. Severini et al. (2016), demonstrated the reliance of EU farmers, especially in small farms, on Direct Payments (DP) delivered by the Common Agricultural Policy (CAP). In accord with drastic reduction in the price sup- port by the CAP for some sectors, the DP was fully appreciable. Thus, in case of changing conditions, such as a rise in expenses in order to meet new environmental or technical demands, there is a need for compensation during that time. As cited by Bowman and Zilberman (2013, p. 5): "Public incentives to adopt environmentally sustainable production methods can help farmers to offset the fixed costs of adopting a new technology".

Beyond the policy makers role in ensuring income stability, the farmers decision-making on income diversification should be accounted for. In accordance with the research literature, income diversification decision depends on farmers characteristics including entrepreneurial skills and values, wealth, risk perception, socio-demographics, as well as the regional and institutional environment in which farms perform at (De Rosa et al., 2019; Demissie and Legesse, 2013; Weltin et al., 2017; Reardon et al.,1992; Bowman and Zilberman, 2013; Stoorvogel et al., 2004; Culas and Mahendrarajah, 2005).

In the context of rural farm diversification, entrepreneurial skills and values determine to what extent farmers exploit on-farm agricultural opportunities and serendipitous events, amongst others. In a case study, relating to diversification opportunities in remote rural area in Italy, De Rosa et al., 2019 attempted to understand the entrepreneurial capability and course of action of farmers and their family. Their main findings are that entrepreneurial process could emerge from serendipity events such as generational renewal and grants or funds for farm diversification that are given as regional rural policy, as well as, acquiring skills to cope with new fields of business such as cooking or tourism. Exploiting opportunities through “... co-align multiple factors to increase performance" (De Rosa et al., 2019, p. 296) i.e., "Resource Orchestration" is found to be a part of the continuous process of strategizing entrepreneurial skills and values and mitigating risk. Dries et al. (2012) found that the presence of a successor indicated tendency to diversify income and thus continuity of the family business.

Considering the farmer's wealth, it is suggested that the wealthier farmers tend to be less risk averse, due to having in land or non-land assets. These resources provide them some sort 
of security while expanding their activities. This diversification compensates for possible income instability in the agricultural sector (Reardon et al.,1992; Newbery and Stiglitz, 1981).

In addition, subsidy, or fixed yearly income, provided by the government, increase farm households' wealth and income. This signifies a decline in risk aversion, consequently, reducing the incentive for working off the farm. This governmental policy plays a role in the farmers decision-making concerning off-farm work (Serra et al., 2005).

Relating to socio-demographic characteristics, education, and age, through cluster analysis, Morris et al. (2017), found that "no off-farm income" cluster 1 consisted of the old age and less educated farmers. These farmers are characterized by limited use of technologies and as reluctant to engage with subsidy opportunities. In reference to studies in Latin America analyzing household participation in rural non-farm employment and income, Reardon et al. (2001), point out, that higher level of education advances nonfarm incomes. As cited by Llewellyn and Brown (2020, p. 107): "Greater efforts to recognize and characterize the education status of a population are likely to improve the ability to predict adoption rates by smallholder farmers, particularly since many have low level of formal education and literacy".

In respect to regional and institutional environment in which farms perform at, within the agricultural sector, regional specialization is frequent. Typically, in some parts of a country, animal production is dominant, while other parts specialized in crop production. Due to specialization, low diversification is expected. Nonetheless, larger farms are more diversified than expected. Controlling for other characteristics, this account for not being sufficient economies of scale to undertake specialization or complying with environmental standards (Culas and Mahendrarajah, 2005).

Dries et al. (2012) demonstrate that farms located in remote mountainous area in Italy, are more prone to diversify income (off-farm activity). Maye et al. (2009) point out that income diversification is essential survival strategy in marginal areas.
Following Newbery and Stiglitz (1981) and Reardon et al. (1992), it is assumed that household utility is a negative function of income instability. Accordingly, the risk perception of households' farms is risk aversion.

Thus, beyond governmental support, in order to stabilize income and hence to avert risk, an income diversification is required. Respectively, any analysis of reforms derivatives should consider farmers income diversification.

This study presents an analysis of farmers income diversification, in the eggs branch in Israel, using insights from the agricultural economics research literature. In practice, the study evaluates the diversification decision by using age, level of education, wealth, and regional features as explanatory variables.

The paper is organized as follows. Section 2 provides a brief description of the poultry sector globally and locally. Section 3 presents the data collected and lays out the empirical approach for data processing and analyzing. Section 4 presents the results. Section 5 concludes.

\section{Poultry sector globally and locally}

Based on the Global Livestock Environmental Assessment Model (GLEAM 2.0, 2016), 73 million tons of eggs and proximity 100 million tons of poultry meat were produced globally in 2016 . Global per capita consumption of eggs and poultry meat increased considerably between 1961 and 2010 (FAOSTAT, 2016). In future outlook on the global poultry production, Mottet and Tempio (2017) particularly relates to the importance of the poultry sector as a key to mitigate poverty and provide economic viability for smallholders. These researchers recommend that policies issued to account for climate change as well as human, animals and environmental impacts, need to consider the smallholders' farms "capacity to react and invest, the cost associated with dissemination, extension and monitoring change and the different entry points for public policies in the different production systems" (Mottet and Tempio, 2017, p. 254).

In Israel, $20 \%$ of the total annually agricultural production, proximity 6,148 million NIS, were produced in the poultry sector by 3600 house- 
Table 1 - Poultry annual production.

\begin{tabular}{|lcccc|}
\hline Poultry branch & Number of producers & Quantity & NIS in millions & Percentage \\
\hline Broiler & 590 & 521,000 tons & 3,425 & $55.7 \%$ \\
Turkey & 85 & 94,000 tons & 633 & $10.3 \%$ \\
Eggs & 2,859 & $(2,186) \times 106$ eggs & 1,124 & $18.3 \%$ \\
Breeding & 66 & $(250) \times 106$ chicks & 966 & $15.7 \%$ \\
Total & 3,600 & & 6,148 & $100 \%$ \\
\hline
\end{tabular}

Source: Israeli Egg and Poultry Council.

holds' farms (Moshavim) and Kibbutzim. Table 1 presents the 2019 annual poultry production distribution along the various branches.

The Israeli poultry sector was operated under heavy regulation indicated by allocation of production quotas. At the beginning of the 90's a farm policy reform has been performed. The reform intentions were increasing production efficiency, decreasing consumer prices while protecting the household's farms.

This reform terminated the regulation in the broiler and turkey branches (the eggs branch remained under regulation). The broiler and turkey producers are mainly the Kibbutzim and the Moshavim farms. This study focuses on the structural changes in the Moshavim.

Figure 1 and Figure 2 describe the structural changes in these branches relating to the number of producers and the production in the Moshavim.
The reform in the broiler branch resulted in an overwhelming decrease in the number of households' farms from 1,311 in 1997 to 332 in 2016 (Figure 1). The actual decrease is more dramatic, since prior to the reform execution, in 1993, the number of producers was 3,000 . The total production increased from 88,214 tons in 1997 to 300,432 tons in 2016 (Figure 1).

The same direction was observed in the turkey branch: a decrease in the number of households' farms from 227 in 1997 to 64 in 2016 (Figure 2); a moderate increase in the total production from 55,768 in 1997 to 59,998 in 2016 (Figure 2).

Considering the structural changes, it is proposed to analyze this process as an impact of the reform which permitted the farmers to trade their quotas. Consequently, some farmers increased their farm at other's expense, some formed partnerships and merged their farms and most

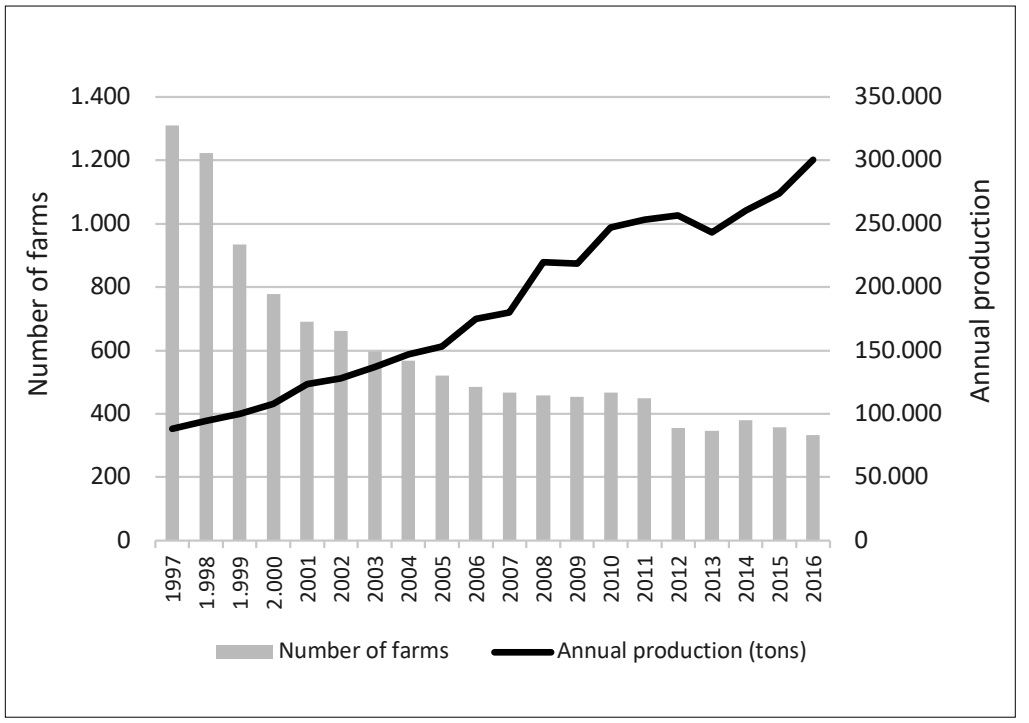

Figure 1 - Structural changes in Broiler's production during the reform.

Source: Israeli Egg and Poultry Council. 


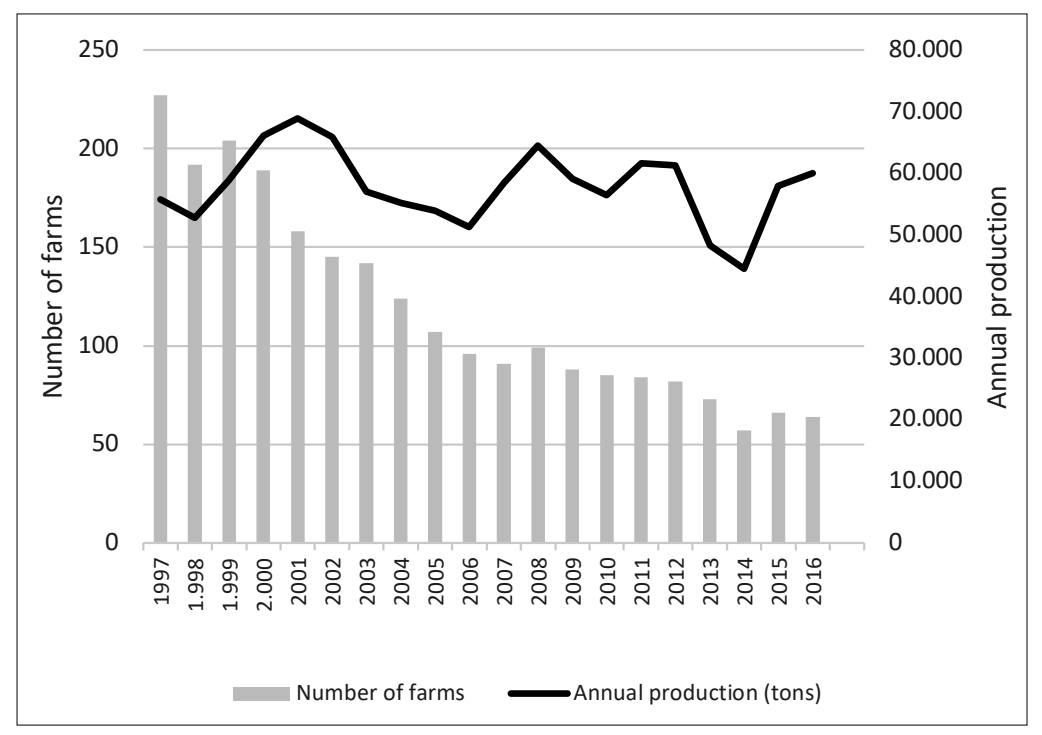

Figure 2 - Structural changes in Turkey's production during the reform.

Source: Israeli Egg and Poultry Council. of the farmers left these branches. Overall, the production is concentrated by a small number of producers and the goal to protect smallholders' farmers economically viable, was missed.

The main research objective of this paper is not just explaining past adoptions of new farming routine, it is predicting adoption or dis-adoption of an emerging agricultural reform in the eggs branch. This is the only branch that remained regulated in the poultry sector.

A trial of farm policy reform in the eggs branch has been carried out in 1994. One of the reform principals was discarding the production limitations as determined by quotas allocation. This principal is the common denominator in past reforms in the dairy sector (Kimhi and Reznik, 2018) as well as in the poultry sector. As discussed previously, this structural change led to massive abandonment of smallholders' farmers. Few years later, minor changes occurred in the eggs branch as quotas' transferring from one farmer to another, still, this branch remained regulated. Thus, the quotas policy, the Galilee farmers' subsidy, and the egg's price supervision, stand unaltered. Accordingly, the number of farmers in the eggs branch hardly changed as opposed to the massive decline in the other poultry branches. Figure 3 describes the number of producers in the Moshavim. In Israel, eggs are produced solely by the Moshav- im farmers, largely in the Galilee and the rest in the center of Israel.

Considerable portion of Moshavim were established in the 50s'. These settlements were populated by immigrants, mostly, in distant areas of the country (Kimhi, 2011). Agriculture has been their prime source of income. Regional specialization occurred within Israeli's eggs branch. In the mountainous parts of Israel, the Galilee and Jerusalem area, egg is the main agricultural branch. The process of regional specialization has taken place in several developed countries. As a case study, Culas and Mahendrarajah (2005) studied this process in Norwegian agriculture, where in some parts of the country, the animal production was dominant, while other parts specialized in crop production.

Government's total commitment to agricultural development, to embracing agriculture as national mission, is considered the first factor of Israeli's success. This commitment stems from ideology, leading to prioritizing, planning, and coordinating programs and policies, resulting in massive agriculture production (Abraham et al., 2019).

Nonetheless, following three and four decades since the 50s' (80s' and 90s'), Moshavim with larger reliance on agriculture are worse off. It is evident that the prioritizing of agriculture and the importance of assuring farmers well-being, have 
Figure 3 - Number of producers in the eggs branch by region.

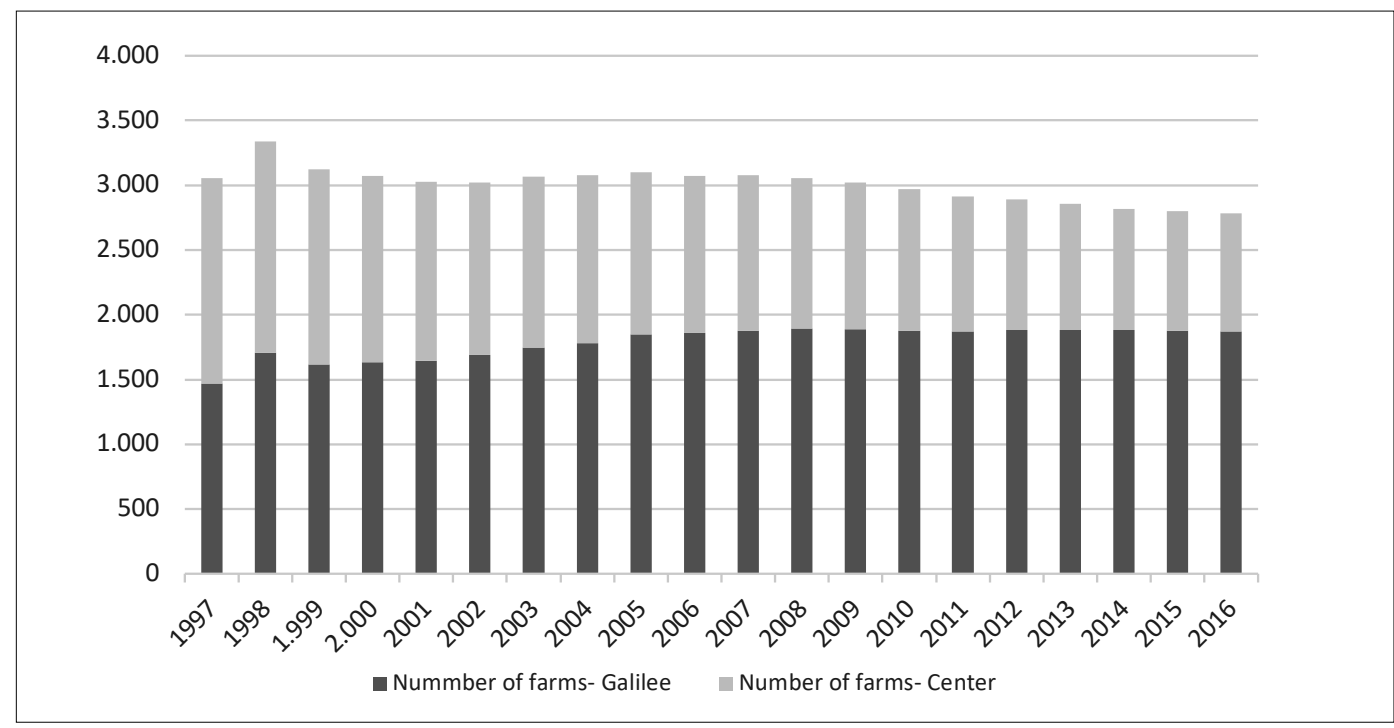

Source: Israeli Egg and Poultry Council.

lessened. Subsequently, in order to maintain the national commitment to agricultural sector, policy makers need to compensate farmers for structural changes occurring in the sector, as cited by Kimhi (2011, p. 40) “... if governments want to keep farmers in business, for the benefit of the entire population, they have to reward them for the public goods they provide indirectly".

The implications of using a new farming practice in the poultry sector in Israel have been neglected in the vast rural and agricultural research literature. This research advances an analysis of adopting new farming as a process. One-fold is explaining the effects of past reforms on the broiler and turkey branches (section 2). The second fold is analyzing implications of future structural changes, in the eggs branch, on farmers behavior (sections 3 and 4).

\section{Data and model specification}

This paper uses survey data from 2016 of 379 eggs branch farmers in six Moshavim in the Galilee region, Israel. The percentage of the eggs branch farmers in the Galilee is $67 \%$ $(1,915)$ of the total $(2,859)$. The survey was designed in accordance with the research purpose, thus, including age (numeric) and educa- tion level of household head (nominal); size of eggs quota (numeric); the Moshav (nominal); the diversifying strategy by participation in non/off-farm employment activities (nominal). The information was manually collected from hardcopies of the survey items. This is a unique data set, in that, for the first time, information on income diversification of eggs farmers in Israel was collected.

\subsection{Data and descriptive statistics}

The mean age is 61 , the mode age is 72 . These statistics are remarkably high. The range of the size of eggs quota is extremely wide. The minimum and maximum quota sizes are 268,000 and $5,841,000$ eggs, respectively. The 75 th and 25 th percentiles equal 614,000 , which signifies one quota, and an interquartile range of zero. Less than 25 percent of the farmers have more than one quota, hence, the analysis relates to coding 0 for having utmost one quota, 1 otherwise. The 0 and 1 categories frequencies are $301(79 \%)$ and $78(21 \%)$, respectively.

It is worth nothing that the price of a quota is extremely high, thus, this variable could be considered as an adequate measure of the households' wealth. 
The sampled Moshavim belong to the same regional council, a primer producer of the eggs branch, located in the Western Galilee. All the Moshavim are categorized as national prioritized region due to proximity to the northern border of Israel. Within the regional council, the Moshavim are not homogeneous in respect to the peripherality indexes, as well as, the distance from the border. Table 2 displays these statistics within the regional council including the number of households in the sampled Moshavim.

The Peripherality Index is a normalized value, calculated by weighted average of potential accessibility index and the proximity to the boundary of the Tel-Aviv district. All the indexes are negative, i.e., below average. This accounts for the fact that all the Moshavim are in the northern periphery of Israel, near the border with Lebanon. The distance from the border is few meters for Moshav 3, $4 \mathrm{~km}$ for Moshav 6 and more than $4.5 \mathrm{~km}$ for the rest of the Moshavim. The index rank indicates the position of the Moshav considering 1,210 localities.

The coding for the nominal variable "education level" is 0 for secondary school or less and 1 for post-secondary education. The 0 and 1 categories frequencies are 317 (84\%) and 62 (16\%), respectively.

All the sampled households are egg producers, income diversification relates to additional income sources, as follows: other agricultural branch (Other), residential or commercial units for long-term rent (Rent), rural accommodations for short-term (Accommodation), household head off-farm activity (Off-farm), spouse's offfarm activity (Spouse). Table 3 displays the income diversification prevalence.

The statistics presented in Table 3 show that the mode of income diversification is "No income diversification", hence, most egg producers $(61.5 \%)$ have no other source of income. Acknowledging that the sum of the various frequencies exceeds 379 , it is evident that the farmers income may be diverse by more than one source. To illustrate, 25 out of 150 farmers in rural accommodations for short-term (Accommodation), engage in another agricultural branch (Other), as well.
Table 2 - The prevalence of eggs branch households' farmers and the peripherality index for each moshav.

\begin{tabular}{|lcc|}
\hline & Peripherality Index (Rank) & Frequency \\
\hline 1 & $-0.63(303)$ & 63 \\
\hline 2 & $-0.67(288)$ & 63 \\
\hline 3 & $-1.03(123)$ & 77 \\
\hline 4 & $-0.76(234)$ & 59 \\
\hline 5 & $-0.75(241)$ & 57 \\
\hline 6 & $-0.79(216)$ & 60 \\
\hline
\end{tabular}

Source: Central Bureau of Statistics (2015).

Table 3 - The prevalence of income diversification.

\begin{tabular}{|lcc|}
\hline & Frequency & Percent \\
\hline $\begin{array}{l}\text { No income } \\
\text { diversification }\end{array}$ & 233 & $61.5 \%$ \\
\hline Other & 94 & $24.8 \%$ \\
\hline Rent & 17 & $4.9 \%$ \\
\hline Accommodation & 150 & $39.6 \%$ \\
\hline Off-farm & 90 & $23.7 \%$ \\
\hline Spouse & 32 & $8.5 \%$ \\
\hline
\end{tabular}

This frequency table indicates that less than $38 \%$ of the farmers have diversified their income, furthermore, the frequency of some categories is extremely low. Subsequently, it is justifiable to transform income diversification to binary variable, coding 0 for absence of income diversification and 1 for its presence.

\subsection{Model specification}

To learn about the relationship between the binary dependent variable - income diversification - and the exogenous variables - age (interval), wealth (binary), Moshav (nominal) and the level of education (binary) - logistic regression (Hosmer and Lemeshow, 2000) and classification tree (CART; Lewis, 2000) were used.

Employing these two techniques provides two different ways of treating the variance in the effect of the exogenous variables. In logistic regression any variable that affects the probability of diversification decision will alter the variance of the observation, hence, the residuals, that is, the difference of the observed diversification decision and the predicted value, are not homog- 
enous across levels of the exogenous variable. Nonetheless, transforming the deviation (the residual) by the function: twice the logarithm of the likelihood function (i.e., $2 \times \log$ (residual)) makes the residuals homogenous across the values of the exogenous variables. Classification trees (hereafter CT) consider the variance in the effect of the exogenous variables by heterogenous manner. It is reducing the variance by pruning of the decision trees, i.e., removing sections of the tree (removing variables and/or values) that provide little power to classify instances.

Furthermore, in line with logistic regression, probabilities are the terms used when inferring from the sample, nonetheless, using CTs enables another mode of thinking. Rather than thinking of probabilities, the terms used are categories, such as "no diversification" versus "diversification" (Lewis, 2000).

\subsubsection{Logistic regression analysis}

This method enables us to estimate the probabilities of diversifying income, i.e. the mean response in binary variable, as a function of the exogenous variables. In line with the research literature, this study hypotheses that the probability of diversifying income is higher amongst young- er, educated, and wealthier farmers. Considering the regional environment effect, this study hypothesized that individual differences between the Moshavim determine the probability of diversifying income, as well. It should be noted that when testing each hypothesis, the other variables are controlled for. The hypotheses testing results are given and discussed in section 4 .

The general form of the logistic model is expressed as follows. Let y represents the binary diversifying income decision. y equals 1 upon diversifying and 0 otherwise. Let $\left(x_{1}, x_{2}, x_{3}, x_{4}\right.$, $\left.x_{5}, x_{6}, x_{7}, x_{8}\right)$ represent the exogenous variables. $x_{1}$ denotes Age (numeric), the coding for $x_{2}, x_{3}$, $x_{4}, x_{5}, x_{6}, x_{7}, x_{8}$ is given in Table 4 .

Let $\mathrm{p}$ denotes the conditional probability (the mean response):

$$
\mathrm{p}=\operatorname{Pr}\left(y=1 \mid x_{1}, x_{2}, x_{3}, x_{4}, x_{5}, x_{6}, x_{7}, x_{8}\right) .
$$

The linear combination of the exogenous variables is as follows:

$$
\begin{gathered}
\beta_{0}+\beta_{1} \cdot x_{1}+\beta_{2} \cdot x_{2}+\beta_{3} \cdot x_{3}+\beta_{4} x_{4}+ \\
\beta_{5} \cdot x_{5}+\beta_{6} \cdot x_{6}+\beta_{7} x_{7}+\beta_{8} \cdot x_{8}
\end{gathered}
$$

The parameters $\beta_{i}\left(\mathrm{i}=0, \ldots, 8, x_{\mathrm{o}}=1\right)$ are the unknown variables weights. To link this linear

\begin{tabular}{|c|c|c|c|c|c|c|}
\hline & & (1) & (2) & (3) & (4) & (5) \\
\hline \multirow{6}{*}{ Moshavim } & $\begin{array}{c}x_{3} \\
\text { (Moshav 1) } \\
\end{array}$ & 1 & 0 & 0 & 0 & 0 \\
\hline & $\begin{array}{c}x_{4} \\
\text { (Moshav 2) } \\
\end{array}$ & 0 & 1 & 0 & 0 & 0 \\
\hline & $\begin{array}{c}x_{5} \\
\text { (Moshav 3) } \\
\end{array}$ & 0 & 0 & 1 & 0 & 0 \\
\hline & $\begin{array}{c}x_{6} \\
\text { (Moshav 5) }\end{array}$ & 0 & 0 & 0 & 1 & 0 \\
\hline & $\begin{array}{c}x_{7} \\
\text { (Moshav 5) }\end{array}$ & 0 & 0 & 0 & 0 & 1 \\
\hline & Moshav 6 (baseline) & 0 & 0 & 0 & 0 & 0 \\
\hline \multirow[b]{2}{*}{ Education: $x_{8}$} & 0 (less educated) & 1 & & & & \\
\hline & 1 (more educated) & $\begin{array}{c}\text { baseline } \\
0\end{array}$ & & & & \\
\hline \multirow[b]{2}{*}{ Wealth: $x_{2}$} & $0($ quota $<=1)$ & 1 & & & & \\
\hline & $1($ quota $>1)$ & $\begin{array}{c}\text { baseline } \\
0 \\
\end{array}$ & & & & \\
\hline
\end{tabular}
combination to the conditional probability, the

Table 4 - Parameter coding. 
term "odds" and the logit function should be defined. The odds of an event are the probability that the event will occur, divided by the probability that it will not occur, odds $=\frac{p}{1-p}$. The logit function is the $\log$ odds of diversifying, $\operatorname{logit}(\mathrm{p})=$ $\log \left[\frac{\mathrm{p}}{1-\mathrm{p}}\right]$. Relating the mean response to the exogenous variables is done in the following way:

$\operatorname{logit}(\mathrm{p})=\beta_{0}+\beta_{1} \cdot x_{1}+\beta_{2} \cdot x_{2}+\beta_{3} \cdot x_{3}+\beta_{4} x_{4}+$ $\beta_{5} \cdot x_{5}+\beta_{6} \cdot x_{6}+\beta_{7} x_{7}+\beta_{8} \cdot x_{8}$.

Extracting $\mathrm{p}$ from this equation yields:

$p=\frac{1}{1+e^{-\left(\beta_{0}+\beta_{1} \cdot x_{1}+\beta_{2} \cdot x_{2}+\beta_{3} \cdot x_{3}+\beta_{4} x_{4}+\beta_{5} \cdot x_{5}+\beta_{6} \cdot x_{6}\right.}}+{ }^{\left.+\beta_{7} x_{7}+\beta_{8} \cdot x_{8}\right)}$

\subsubsection{Classification Tree analysis}

A CT analysis is a tree-building technique for generating decision rules. It is composed of a root node, internal nodes, and leaf node. The final decision or prediction taken after following the path from root to leaf (expressed as a classification rule) is represented by leaf nodes.

The analysis is a form of binary recursive partitioning. That is, the root node that includes all the dataset can be split into two subsets, over and over again (recursively), forming additional subsets. The partitioning algorithm splits the data to an increasingly homogenous subsets (purer subsets) with respect to the possible outcomes (binary) of the dependent variable. There are several methods that could be employed for search of the variables that best split the dataset, i.e. the variables that creates increasingly homogenous subsets, purer subsets. This study's classification tree was created using Information Gain theory algorithm for identifying the best splitter by WEKA software. According to Information Gain theory, the criteria for finding the best split is the variable that decreases the entropy, i.e. the uncertainty, that accounts for greater information gain. This is illustrated as follows.

Let Entropy $(\mathrm{t})$ represent the entropy of diversifying income decision. $t$ equals 1 upon diversifying and 0 otherwise. Let $p(1), p(0)$ denotes the prevalence of observations that choose to diversify and to not diversify, respectively. Thus, the entropy of diversifying income decision is defined by

Entropy $(\mathrm{t})=-\mathrm{p}(0) \cdot \log _{2}(\mathrm{p}(0))-\mathrm{p}(1) \cdot \log _{2}(\mathrm{p}(1))$ let $n_{i}$ denotes the $i_{\text {th }}$ subsample size of an exogenous variable $(\mathrm{i}=0,1, \ldots, \mathrm{k}), \mathrm{n}$ the sample size and Entropy(i) the entropy of diversifying income decision upon splitting by the exogenous variable. The information gain (IG) is calculated by

IG $(\mathrm{t}$, split by an exogenous variable $)=$

$$
\text { : Entropy(t)- }\left(\sum_{i=1}^{k} \frac{n_{i}}{n}(\operatorname{Entropy}(\mathrm{i}))\right) \text {. }
$$

The following is an example of the use of IG when splitting by Education. The input for this example is given by Diversification * Education Crosstabulation in Table 5.

\section{Entropy $(\mathrm{t})=$}

$-\left(\frac{233}{379}\right) \cdot \log _{2}\left(\frac{233}{379}\right)-\left(\frac{146}{379}\right) \cdot \log _{2}\left(\frac{146}{379}\right)=0.96$ Entropy $(\mathrm{i}=0$, Education $)=$

$$
\begin{gathered}
-\left(\frac{206}{317}\right) \cdot \log _{2}\left(\frac{206}{317}\right)-\left(\frac{111}{317}\right) \cdot \log _{2}\left(\frac{111}{317}\right)=0.93 \\
\text { Entropy }(\mathrm{i}=1, \text { Education })= \\
-\left(\frac{27}{62}\right) \cdot \log _{2}\left(\frac{27}{62}\right)-\left(\frac{35}{62}\right) \cdot \log _{2}\left(\frac{35}{62}\right)=0.99 \\
\text { IG }(\mathrm{t}, \text { split by Education })= \\
0.96-\left(\frac{317}{379}\right) \cdot(0.934)-\left(\frac{62}{379}\right) \cdot(0.99)= \\
0.96-0.94=0.02
\end{gathered}
$$

The entropy of diversifying income decision upon splitting by the nominal exogenous variables is 0.96 for Wealth and 0.89 for Moshav, thus, IG ( $t$, split by Moshav) is the highest. Considering these three variables, as a starter split to predict the diversification decision, Moshav should be chosen. Acknowledging that there is another exogenous variable (Age), the analysis must consider the IG of all four variables. The WEKA software is used to determine the starter split.

\section{Results and discussion}

\subsection{Predictions of diversifying income probabilities}

Following logistic regression approach Table 5 displays Diversification * Exogenous variable crosstabulation.

This table sums up the data in this research in a way that is coherent with the logistic regression analysis. For example, the odds of a less 
Table 5 - Diversification * Exogenous variable crosstabulation.

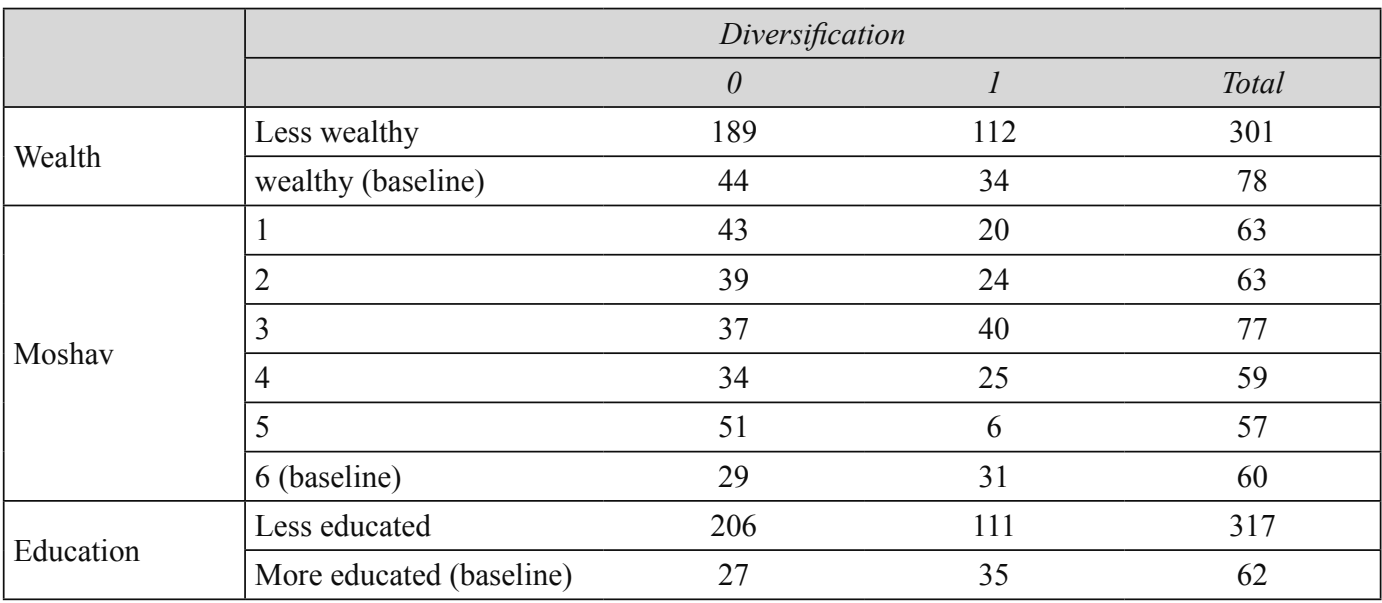

wealthy farmer to diversify income are 0.77 times the odds of a wealthy one (baseline). The odds ratio is calculated by $\frac{112 / 189}{34 / 44}=0.77$, thus, the estimator of the Wealth coefficient $\beta_{2}$ equals -0.27 . The negative sign of the estimator means that the transition from the wealthy farmer to the less wealthy reduces the level of diversification. It follows that the probability of a less wealthy farmer to diversify equals $\frac{0.767}{1+0.767}=0.43$, equally, the probability of a wealthy farmer to diversify equals 0.57 . For the sake of simplicity, the above calculations are under the assumption that Wealth is the only exogenous variable in the model. Acknowledging that there is more than one exogenous variable, the analysis must consider the impact of all the additional variables. Table 6 presents the estimators, $\beta_{i}$, for each variable in the model as calculated by Statistical Package for the Social Sciences (SPSS) software.

Relating to the research hypothesis given in section 3, the probability of diversifying income is higher amongst younger, educated, and wealthier farmers with individual differences between the Moshavim logistic regression verifies this conjecture. Particularly, the odds ratio $(\beta \mathrm{s})$ of a farmer to diversify is negatively related significantly to his wealth $\left(\widehat{\beta}_{2}=-0.69, p<0.05\right)$, and education $\left(\widehat{\beta_{8}}=-0.62, P<0.05\right)$ that is, the transition from the wealthy and/or the educated farmer to the less wealthy and/or less educated one reduces the level of diversification. Simi- larly, the older are less likely to diverse income $\left(\widehat{\beta}_{1}=-0.03, p<0.05\right)$. Further, relating to Moshav 6 and given the same age, wealth and education scores, a farmer in Moshav $1\left(\widehat{\beta}_{3}=-0.99\right.$, $p<0.05)$, Moshav $2\left(\widehat{\beta}_{4}=-0.87, p<0.05\right)$, and Moshav $5\left(\widehat{\beta}_{7}=-2.61, p<0.001\right)$ is significantly less likely to diversify income. The negative

Table 6 - Results from logistic regression analysis using exogenous variables for estimating diversifying income.

\begin{tabular}{|lcc|}
\hline Variables & $\begin{array}{c}\text { Coefficients } \\
(\beta)\end{array}$ & $\begin{array}{c}\text { Significance } \\
\text { Level }(p)\end{array}$ \\
\hline Constant & 3.18 & $0.000^{* *}$ \\
\hline Age & -0.03 & $0.002^{*}$ \\
\hline $\begin{array}{l}\text { Wealth } \\
\text { Baseline: (quota }>1)\end{array}$ & -0.69 & $0.02^{*}$ \\
\hline Moshav 1 & -0.99 & $0.013^{*}$ \\
\hline Moshav 2 & -0.87 & $0.028^{*}$ \\
\hline Moshav 3 & -0.37 & 0.318 \\
\hline Moshav 4 & -0.73 & 0.062 \\
\hline Moshav 5 & -2.66 & $0.000^{* *}$ \\
\hline $\begin{array}{l}\text { Education } \\
\text { (baseline: post- } \\
\text { secondary education) }\end{array}$ & -0.62 & $0.044^{*}$ \\
\hline
\end{tabular}

Notes: $* p<0.05, * * p<0.001$. Dependent variable: $d i-$ versification decision; Model: Constant, age, wealth, Moshav, education. All significant coefficients' Wald chi-square are above 2. The values of minus $2 \log$ (likelihood) and chi-square are 438.883, $3.856(p=0.870)$ respectively. Cox and Snell $R^{2}=0.144$. Nagelkerke $R^{2}=0.195$. 
relationship of the farmers of Moshav $3\left(\widehat{\beta}_{5}=-\right.$ $0.37, p>0.05)$ and Moshav $4\left(\widehat{\beta}_{6}=-0.73, p>\right.$ $0.05)$ to diversify income is not significant.

Determining that the $\beta s$ are significant means the logistic regression model predicts the probability of diversification decision better than its mean. The meaning of this is using the odds ratios for the nominal and the numeric predictors. This model is demonstrated in the following calculations:

For a less wealthy, less educated, farmer of age 61 who leaves in Moshav 1, the probability of diversifying income is estimated as:

$$
p=\frac{1}{1+e-(3.18+(-0.03) \cdot(61)+(-0.69)(1)+(-0.99) \cdot}=0.28
$$

For a wealthy, less educated, farmer of age 61 who leaves in Moshav 1, the probability of diversifying income is estimated as:

$$
p=\frac{1}{1+e-(3.18+(-0.03) \cdot(61)+0+(-0.99) \cdot(1)}+0.44
$$

Overall, the more quotas the farmer owns (the wealthier the farmer is) the level of diversification is higher.

For a less wealthy, less educated, farmer of age 61 who leaves in Moshav 3, the probability of diversifying income is estimated as:

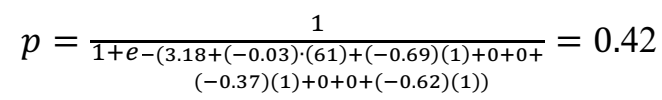

Relating to individual differences between the peripherality of the Moshavim, as illustrated in the two probabilities: $0.28,0.42$, for Moshavim 1 and 3, respectively, the probability of diversifying in Moshav 3 is higher compared to Moshav 1.

\subsection{Predictions of diversifying income decision}

Considering the purpose of predicting the diversifying decision, by employing Information Gain theory as the criteria for finding the best split, CT model selected Moshav as the best predictor, as presented in Figure 4 for starter split.

The terminal nodes are framed with double lines and a single bold line for the decision to diversify income (1) and to not-diversify (0), respectively.

The branch of this root node comprises of the whole training samplings. Thereafter, the process of building up the tree consists of producing splitting rules. Evidently, the next best predictor after the Moshav is Wealth for Moshavim 1 and 6 and Education for Moshavim 2 to 4. Figure 4 presents the entire splitting rules and the final decisions.

Apparently, there are few homogenous or pure subsets in respect to diversifying decision. The terminal node in one pure subset is "not diversify" concerning farmers in Moshav 1 that are wealthy (quota $\geq 1$ ), less educated and older than 60 years of age. The terminal node in four pure subsets is "diversify" concerning farmers in Moshav 6 that are wealthy; farmers in Moshav 1 that are wealthy, less educated and younger than 60 years of age; farmers in Moshav 2 that are less educated, wealthy and older than 64 years of age; farmers in Moshav 3, educated and younger than 30 years of age.

Following the path from root to leaf, several subsets are impure. Succeeding the first split by Moshav, the final decision for Moshav 5 is "not diversify" with misclassification rate of $10.5 \%$ (6/57). The second-best split for Moshav 4 is by Education leading to terminal node at "not diversifying" if the farmer is less educated and "diversifying" if he is educated; misclassification rates are $37 \%$ and $38 \%$, respectively. The final decision for Moshavim 2 and 3 is "not diversify" for less educated and less wealthy farmers with misclassification rates of $47 \%$ and $22 \%$, respectively.

All in all, relating to the validity of predicted instances in the CT method, 241 (64\%) and 138 $(36 \%)$ were correctly and incorrectly classified.

In interpreting the overall results, we recall that the old aged and less educated farmers are prone to not-diversify income (Morris et al., 2017; Llewellyn and Brown, 2020; Reardon et al., 2001), thus, the empirical findings in the present study give an additional support to the research literature.

In case of the Moshav effect, there are individual differences, regarding peripherality, in diversifying income. Within the agricultural sec- 
Figure 4 - Determination of diversifying decision using CT analysis.

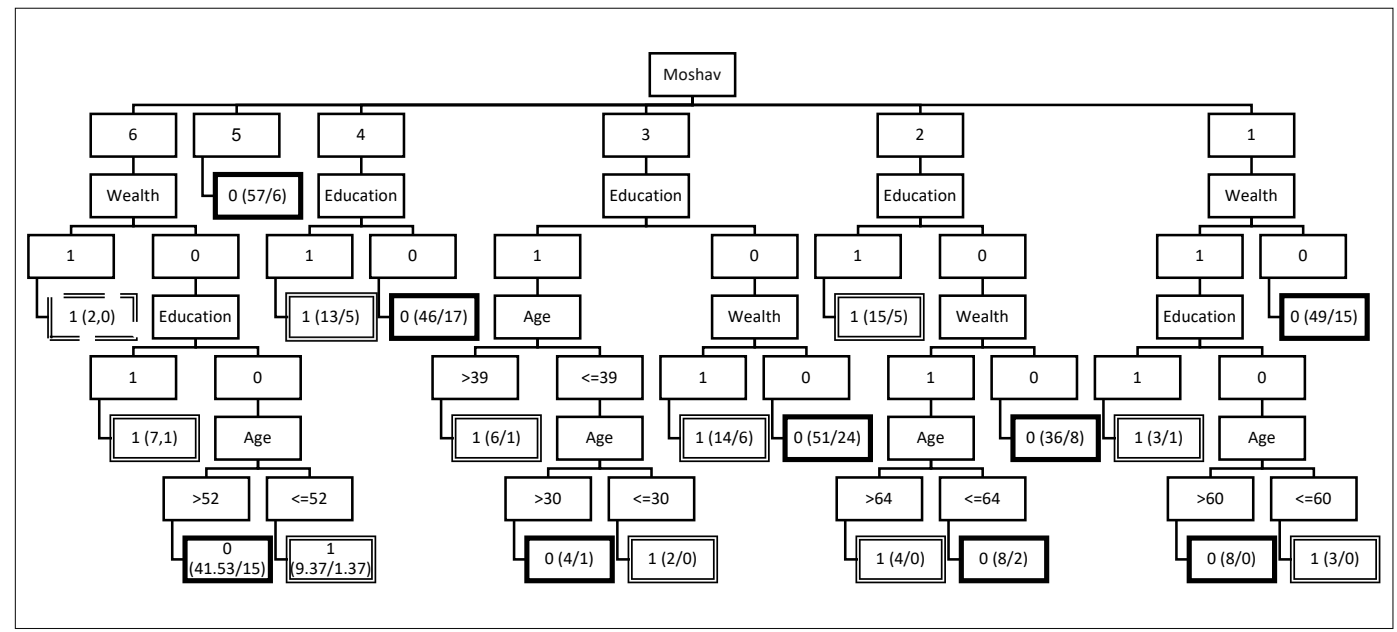

tor, regional specialization is frequent, thus, low diversification is expected (Culas and Mahendrarajah, 2005). In this study, it is evident that the more remote the Moshav, the farmer is more likely to diversify income. This research innovative approach is that the higher the peripherality of the rural village is, so is the farmers tendency to avert risk. A possible strategy to reduce risk is to diversify income.

Expectations of farmers could be additional variable adequate to analyze diversifying decision. Expanding the spectrum of controlled variables, could result in a reduction of unexplained variance or incorrectly classified instances. It is plausible to consider these variables when rationalizing the evolution of the Moshavim's establishment and the eggs branch in the Galilee region. Government's historical commitment to embracing agriculture and rural settlement as national mission, formed implicit expectations among the farmers that the government is obligated towards their sustainability and viability. This variable was not measured in the current research.

\section{Conclusions}

This study aims to assess the ability of farmers to remain economically viable, by analyzing farmers income diversification strategies.

Past farm policy reforms in the poultry sector, excluding the eggs branch, resulted in a rapid exit of smallholders' farms. Addressing issues regarding the farmers ability to cope with changing conditions arising from implementing these past reforms, is highly relevant to predict the farmers survival considering the planned eggs farms reform. The binary diversifying income decision is evaluated for a sample of farm households in Israeli periphery. The research uses logistic regression and classification tree as methods of data analysis. The main findings signify that the younger, educated, and wealthier farmers who are more peripheral, prone towards diversifying income. Regarding classification tree method, these results conform the paths derived from the initially best predictor - the Moshav - to the leaf nodes.

Lessons should be learned from past reforms and from this study determinants of diversifying decision. The threat of canceling regulation that resulted in voluminous exit of smallholders' farms, as recognized in past reforms, is genuine. The profile of the farmer that chooses to not diversify income, as well as, the variability in the peripherality index, needs to be considered by policymakers when implementing new reforms. One main area of consideration should be endowing the farmers that "put all the eggs in one basket", by direct payments. Another area of consideration should be incentivizing the next generations (generational renewal) to preserve the family farm and the local production. The 
outburst of COVID-19 intensifies the importance of reliance on local eggs production.

This research proposes a theoretical framework for predicting and explaining reforms economic implications, considering income diversification strategy of farmers. Future studies may apply this research methodology and theory to analyze farmers economic viability using other types of rural populations in the periphery.

Future studies may analyze farmers economic viability using additional insights from classical and behavioral economics (Pannell and Zilberman, 2020) such as farmers risk perceptions or expectations. Following De Rosa et al. (2019), in order to conduct unsupervised research, a qualitative methodology based on a case study of one family farm in rural Israel needs to be carried on.

\section{References}

Abraham D., Ngoga T., Said J., Yachin M., 2019. How Israel became a world leader in agriculture and water Insights for today's developing countries. London: Tony Blair Institute for Global Change.

Bowman M.S., Zilberman D., 2013. Economic factors affecting diversified farming systems. Ecology and Society, 18(1): 33.

Brouder P., 2013. Tourism development in peripheral areas: Processes of local innovation and change in Northern Sweden. Unpublished doctoral dissertation, Mid Sweden University, Sweden.

Culas R.J., Mahendrarajah M., 2005. Causes of Diversification in Agriculture Over Time: Evidence from Norwegian Farming Sector. Paper presented at the 11th Congress of the EAAE (European Association of Agricultural Economists), 'The Future of Rural Europe in the Global Agri-Food System', August 24-27, Copenhagen, Denmark.

Demissie A., Legesse B., 2013. Determinants of income diversification among rural households: The case of smallholder farmers in Fedis district, Eastern hararghe zone, Ethiopia. Journal of Development and Agricultural Economics, 5(3): 120-128.

De Rosa M., McElwee G., Smith R., 2019. Farm diversification strategies in response to rural policy: A case from rural Italy. Land Use Policy, 81: 291-301.

Dries L., Pascucci S., Gardebroek C., 2012. Diversification in Italian farm systems: Are farmers using interlinked strategies. New Medit, 11(4): 7-15.

Fleischer A., Tchetchik A., Bar-Nahum Z., 2018. Is agriculture important to agritourism? The agritour- ism attraction market in Israel. European Review of Agricultural Economics, 45(2): 273-296.

Hill B., 1993. The 'Myth' of the Family Farm: Defining the Family Farm and Assessing its Importance un the European Community. Journal of Rural Studies, 9(4): 359-370.

Hosmer D.W., Lemeshow S., 2000. Applied Logistic Regression. New York: John Wiley and Sons Inc.

Kimhi A., 2011. The Role of Agriculture in Rural Well-Being: The Case of Israel. New Medit, 10(2): 33-41.

Kimhi A., Reznik A., 2018. Efficiency Implications of the Dairy Farm Policy Reform in Israel. Discussion Paper No. 3.18, The Center for Agricultural Economic Research, Rehovot, The Hebrew University of Jerusalem.

Laven D., Chekalina T., Fuchs M., Margaryan L., Varley P., Taylor S., 2019. Building the slow adventure brand in the northern periphery. In: Cassinger C., Lucarelli A., Gyimóthy S. (eds.), The Nordic Wave in Place Branding: Poetics, Practices, Politics. Cheltenham, UK-Northampton, MA: Edward Elgar Publishing Limited, pp. 76-90.

Lewis R.J., 2000. An Introduction to Classification and Regression Tree (CART) Analysis. Paper presented at the Annual Meetings of the Society for Academic Emergency Medicine. San Francisco, California.

Llewellyn R.S., Brown B., 2020. Predicting Adoption of Innovations by Farmers: What is Different in Smallholder Agriculture? Applied Economic Perspectives and Policy, 42(1): 100-112.

Maye D., Ilbery B., Watts D., 2009. Farm diversification, tenancy and CAP reform: Results from a survey of tenant farmers in England. Journal of Rural Studies, 25: 333-342.

Mishra A.K., Goodwin B.K., 1997. Farm Income Variability and the Supply of Off-Farm Labor. American Journal of Agricultural Economy, 79: 880-887.

Morris W., Henley A., Dowell D., 2017. Farm diversification, entrepreneurship and technology adoption: Analysis of upland farmers in Wales. Journal of Rural Studies, 53: 132-143.

Mottet A., Tempio G., 2017. Global poultry production: current state and future outlook and challenges. World's Poultry Science Journal, 73: 245-256.

Müller D.K., Jansson B. (eds.), 2006. Tourism in peripheries: perspectives from the far north and south. Wallingford: Cabi.

Newbery D., Stiglitz J., 1981. The Theory of Commodity Price Stabilization: A Study in the Economics of Risk. Oxford: Clarendon Press. 
Pannell D., Zilberman D., 2020. Understanding Adoption of Innovations and Behavior Change to Improve Agricultural Policy. Applied Economic Perspectives and Policy, 42(1): 3-7.

Præstholm S., Kristensen S.P., 2007. Farmers as Initiators and Farms as Attractors for Non-agricultural Activities in Peri-urban Areas in Denmark. Geografisk Tidsskrift, Danish Journal of Geography, 107(2): 13-27.

Reardon, T., Berdegué J., Escobar G., 2001. Rural nonfarm employment and income in Latin America: Overview and policy implications. World Development, 29(3): 395-409.

Reardon T., Delgado C., Malton P., 1992. Determinants and Effects of Income Diversification amongst Farm Households in Burkina Faso. Journal of Development Studies, 28(2): 264-296.
Serra T., Goodwin B.K., Featherstone A.M., 2005. Agricultural Policy Reform and Off-farm Labour Decisions. Journal of Agricultural Economics, 56(2): 271-285.

Severini S., Tantari A., Di Tommaso G., 2016. Do CAP direct payments stabilise farm income? Empirical evidences from a constant sample of Italian farms. Agricultural and Food Economics, 4(6): 1-17.

Stoorvogel J., Antle J.M., Crissman C., Bowen W., 2004. The tradeoff analysis model: integrated bio-physical and economic modeling of agricultural production systems. Agricultural Systems, 80: 43-66.

Weltin M., Zasada I., Franke C., Piorr A., Raggi M., 2017. Analysing behavioural differences of farm households: An example of income diversification strategies based on European farm survey data. Land Use Policy, 62: 172-184. 